\title{
EXPERT ADVISOR FOREIGN EXCHANGE MENGGUNAKAN SIMPLE MOVING AVERAGE
}

\author{
${ }^{1}$ Suratman \\ Sekolah Tinggi Teknologi Indonesia, Jurusan Teknik Informatika \\ Email : ${ }^{1}$ Suratmanchen@gmail.com
}

\begin{abstract}
ABSTRAK
Foreign exchange (forex) trading adalah transaksi perdagangan nilai tukar mata uang asing di pasar uang internasional, pada saat ini perdagangan foreign exchange banyak diminati oleh masyrakat luas. Pada dasarnya trading forex (foreign exchange) dilakukan secara manual, sehingga hal itu membutuhkan pemantauan grafik harga secara terus-menerus pada layar monitor dan tentu saja itu membuang waktu dan tenaga serta psikologi trader sendiri.

Berdasarkan permasalahan yang ada, penulis melakukan analisa dan merancang expert advisor menggunakan indikator simple moving average yang mengantisipasi kelemahan-kelemahan pada trading manual.Perancangan expertadvisor menggunakan indikator simple moving average yang penulis usulkan telah menjawab permasalahan yang ada. Dengan demikian expert advisor ini akan memberikan hasil yang baik dalam trading.

Software yang digunakan sebagai alat bantu dalam penelitian ini adalah menggunakan metaeditor dan metatrader 4, metodologi yang digunakan untuk pengembangan expert advisor ini adalah menggunakan metode sekuensial linier.
\end{abstract}

Kata kunci : forex, trading, expert advisor, simple moving average, trader

\section{PENDAHULUAN}

Perdagangan forex(Foreign Exchange) atau valuta asing (valas), saat ini perdagangan foreign exchange banyak diminati oleh masyrakat luas, salah satunya di Negara kita, Indonesia.Foreign exchange tradingadalah transaksi perdagangan nilai tukar mata uang asing di pasar uang internasional. Pasar foreign exchange(forex) dibuka 24 jam sehari selama 5 hari dalam seminggu, pasar valuta asing telah mengalami perkembangan yang sangat pesat.

Pada dasarnya trading forex (foreign exchange) dilakukan secara manual, sehingga hal itu membutuhkan pemantauan grafik harga secara terus-menerus pada layar monitor dan tentu saja itu membuang waktu dan tenaga serta psikologi trader itu sendiri. Dengan adanya robot foreign exchange hal itu dapat diminimalisasi, Robot foreign exchange(Expert Advisor) yang telah disediakan pada platform tradingMetaTrader 4 yang dibuat menggunakan bahasa pemrograman MQL (Meta Quotes Language) yang masih satu keluarga dengan bahasa $\mathrm{C} / \mathrm{C}++$.

Dengan adanya fitur Robot foreign exchange ini diharapkan dapat memudahkan dalam pengambilan keputusan dalam trading dan mengatasi kelemahan dari sifat manusia dalam bertrading, seperti, rasa lelah, takut, serakah, tidak konsisten / Disiplin. Perlu diingat bahwa trader itu sendiri tidak dapat sepenuhnya bergantung terhadap Expert Advisor tanpa mengerti cara, dasar, dan mekanisme trading foreign exchange itu sendiri.Berdasarkan uraian tersebut maka penulis tertarik untuk melakukan penelitian dan menuangkannya ke dalam bentuk 
laporan skripsi ini dengan judul " Expert Advisor Foreign Exchange Menggunakan Simple Moving Average" dan diharapkan hasil penelitian skripsi ini dapat berguna untuk masyarakat dalam memahami penggunaan expert advisor dalam perdagangan foreign exchange.

\section{KAJIAN PUSTAKA}

\subsection{Struktur Investasi}

Pada tahun 1970-an hingga akhir 1990-an, sebagian besar pemilik uang lebih memilih menanamkan uangnya di sektor rill, seperti mendirikan pabrik (manufaktur), perumahan, pertanian, perkebunan, perdagangan, dan lain - lain. Baru setelah krisis moneter yang menimpa Indonesia tahun 1997 - 2000, para pemodal mulai mencari investasi lain yang menghasilkan return lebih tinggi dalam tempo yang singkat. Saat itulah, investasi di sektor financial (financial investment) mulai berkembang bahkan mengalami booming di Indonesia.

\subsection{Mekanisme Pasar Foreign Exchange}

Pasar foreign exchange merupakan pasar yang memiliki aktivitas terbesar dan paling likuid di dunia saat ini. Pasar ini beroperasi selama 24 jam penuh dalam sehari dan 5 hari dalam seminggu. Sebagai Produk OTC (Over the Counter), foreign exchangemarket bergerak mulai dari Australia, Asia, Eropa, dan Amerika secara terus-menerus. Pasar foreign exchange beroperasi tanpa lokasi fisik dan tidak memiliki bursa terpusat. Operasinya terjadi melalui jaringan global bank (Major Bank), perusahaan, dan individu-individu yang melakukan pertukaran antara satu mata uang dan mata uang yang lainnya. Tidak adanya lokasi fisik memungkinkan pasar ini beroperasi 24 jam, bergerak dari satu zone waktu ke zone waktu lainnya di berbagai pusat keuangan dunia.

\subsection{Sejarah Trading Foreign Exchange Online}

Hingga awal tahun 1990-an, perdagangan foreign exchange hanya dapat diikuti oleh institusi dan pemain dengan modal besar.Munculnya media internet membawa perubahan besar dalam transaksi foreign exchange.Sekarang, melakukan spekulasi foreign exchange online trading (FOT) melalui internet menjadi jauh lebih praktis, pemain tinggal menitipkan uangnya ke pihak broker, lalu dengan software yang terhubung dengan komputer broker tersebut transaksi sudah dapat dilakukan di mana pun si pemain berada.

\subsection{Pengertian Foreign Exchange}

Trading foreign exchange adalah perdagangan mata uang suatu Negara dengan mata uang Negara lain. Sebagai contoh, di Eropa mata uang beredar adalah Euro (EUR) dan di Amerika Serikat Dolar AS (USD), yang disebut perdagangan foreign exchange adalah pada saat yang bersamaan kita membeli euro dan menjual dolar, disingkat EUR/USD.

\subsection{Pelaku Pasar (Market Maker)}

Pelaku pasar foreign exchange berasal dari berbagai golongan di antaranya Pelanggan (perusahaan mutinasional, perusahaan asuransi, dan lain - lain), Bank dan lembaga keuangan, Broker, Pemerintah (Bank sentral, Bank komersial), Pelaku bisnis (Importir, Eksportir), Spekulan (Big boys), seperti George Soros, Warren Buffet, dan lain - lain. 


\subsection{Perbandingan Trading Foreign Exchange dengan Investasi Rill 1. Jangka Waktu}

Masa berlaku keputusan investasi memiliki rentang waktu yang panjang dan mengikat hingga mencapai tingkat keuntungan ideal sedangkan, Trading Anda dapat langsung melakukan aksi jual tanpa harus direpotkan oleh delay atau proses birokrasi apa pun. Hal ini bisa dilakukan kapan saja tanpa terikat waktu selama sesi perdagangan sedang aktif.

\section{Likuiditas}

Dalam dunia investasi, likuiditas trading merupakan sebuah alat investasi berarti yang menggambarkan luas pasar transaksi terhadap instrumen tersebut (rasio jumlah penjual dan pembeli). Semakin tinggi likuiditas, maka bertambah mudah pula proses trading transaksi dapat dilakukan. Likuiditas yang rendah membawa kesulitan bagi penjual untuk menemukan pembeli.

\section{Potensi Keuntungan}

Dalam investasi tradisional, tidak terdapat fasilitas leverage karena berbasis modal penuh. Leverage merupakan layanan bagi investor untuk melakukan pembelian suatu instrumen trading dengan hanya mengeluarkan modal investasi jauh lebih kecil dari harga instrumen tersebut. Dalam perdagangan derivatif, sebuah instrumen trading berjangka dapat dibeli dengan hanya modal $10 \%$ dari nilai instrumen bahkan ada produk yang dapat dibeli dengan hanya mengeluarkan $1 \%$ modal dari nilai total.

\subsection{Kelebihan Trading Foreign Exchange}

1. Ukuran pasar likuiditas tinggi. Kapan pun Anda ingin menjual, Anda boleh yakin bahwa setiap saat akan selalu ada pembeli untuk itu.

2. Pasar buka 24 jam, 5 hari seminggu dengan akses non-stop untuk dealer foreign exchange global.

3. Anda sedang berada di sebuah pasar besar yang memiliki sifat liquid, sehingga mudah untuk diperdagangkan. Intinya, hasil transaksi dapat segera dieksekusi tanpa adanya delay order dan menunjukkan transparansi pergerakan harga.

4. Volatilitas pasar (harga naik turun) menawarkan peluang keuntungan yang besar. Karena dalam trading foreign exchangeharga naik turun. Dari pasangan mata uang yang melemah dan menguat kita bisa mendapatkan peluang profit.

5. Memiliki standar instrumen untuk eksposur pengendalian risiko (risk management).

6. Adanya leverage perdagangan. Sistem leverage (daya ungkit) inilah yang memungkinkan para trader dengan margin deposit terbatas dapat melakukan kontrak transaksi dengan jumlah besar. Hal ini memberikan kesempatan bagi trader untuk memperoleh keuntungan berlipat. Anda dimungkinkan bertransaksi dengan sistem margin trading dan bisa melakukan transaksi sebesar 10.000 unit hanya dengan 100 USD. 
7. Banyak pilihan untuk perdagangan dengan komisi untuk broker nol dan tanpa swap.

8. Foreign exchange market merupakan sebuah pasar dengan pertumbuhan tercepat abad ini.

9. Dalam beberapa tahun terakhir, foreign exchange menjadi salah satu produk paling populer dan banyak diminati untuk diperdagangkan dan tidak ada market lain selain foreign exchange yang dapat mengalami perkembangan pesat hanya dalam waktu 3 tahun.

\subsection{Perbandingan antara Trading Foreign Exchange dan Saham}

Berikut perbedaanTrading Foreign Exchange dan Saham, yaitu sebagai berikut :

Tabel 2.1 Perbandingan Foreign Exchange dan Saham

\begin{tabular}{|lcc|}
\hline & Foreign Exchange & Saham \\
\hline 24 jam nonstop & Ya & Tidak \\
\hline Kapitalisasi & Tidak terbatas & Terbatas \\
\hline Likuiditas & Ya & Saham tertentu \\
\hline Kecepatan & Tidak perlu antre & Antre \\
\hline Pergerakan Harga & Keuntungan 2 arah & Hanya saat naik saja \\
\hline Pengaruh & Bebas pengaruh & Bandar / Rumor \\
\hline Skop & Global / Dunia & Terbatas hanya pada \\
& & negara \\
\hline
\end{tabular}

\subsection{Waktu Trading Foreign Exchange}

Dalam trading waktu ini dibagi menjadi beberapa sesi perdagangan besar / utama, untuk lebih jelasnya mari kita lihat waktu dan jam kapan masing masing pasar buka / tutup.

Tabel 2.2 Jadwal Waktu Perdagangan Foreign Exchange

\begin{tabular}{|lllr|}
\multicolumn{1}{|c}{ Sesi/Pasar } & \multicolumn{1}{c}{$\begin{array}{c}\text { Jakarta } \\
\text { GMT+7 }\end{array}$} & EST & GMT \\
\hline Sydney Buka & 04.00 Pagi & 04.00 PM & 09.00 PM \\
Sydney Tutup & 12.00 Siang & 02.00 AM & 07.00 AM \\
\hline Tokyo Buka & 06.00 Pagi & 06.00 PM & $11.00 \mathrm{AM}$ \\
Tokyo Tutup & 02.00 Siang & 04.00 AM & $09.00 \mathrm{AM}$ \\
\hline London Buka & 02.00 Siang & 03.00 AM & 08.00 AM \\
\hline
\end{tabular}




\begin{tabular}{|llll|}
\hline London Tutup & 10.00 Malam & $12.00 \mathrm{PM}$ & $05.00 \mathrm{PM}$ \\
\hline New York Buka & 07.00 Malam & $08.00 \mathrm{AM}$ & $12.00 \mathrm{PM}$ \\
New York & 03.00 Pagi & $05.00 \mathrm{PM}$ & $10.00 \mathrm{PM}$ \\
Tutup & & & \\
\hline
\end{tabular}

Tabel 2.3 Jadwal Waktu Perdagangan Foreign Exchange GMT+7

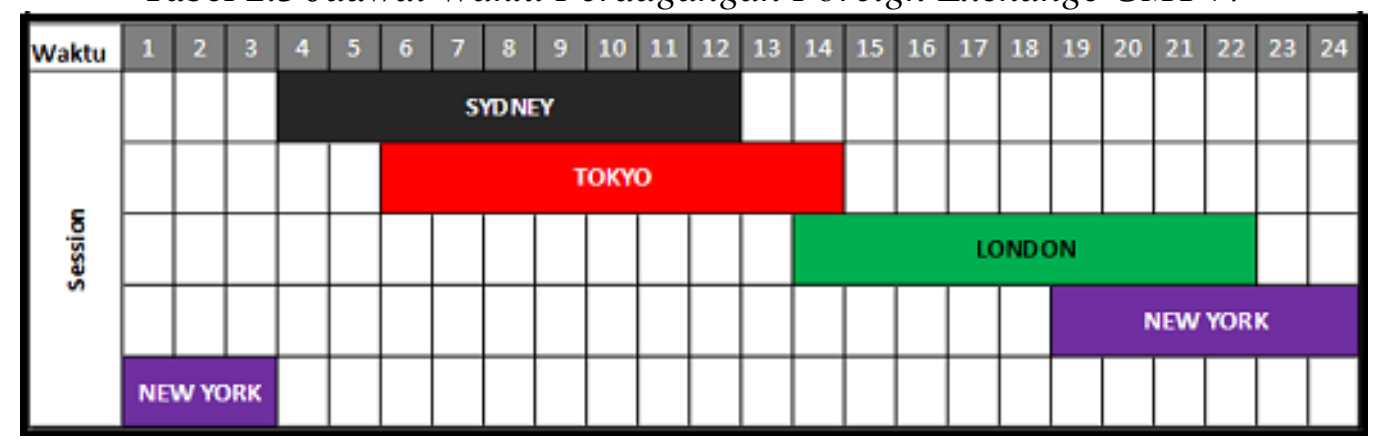

\subsection{Konsep Analisis dalam Trading \\ 2.10.1 Analisis Teknikal}

Analisis teknikal adalah analisis yang menggunakan chart, trend line, indikator (Moving average, Moving average Convergence Divergence (MACD), Relative strength Index (RSI), Bollinger Band, Fibbonaci, Camarilla, Pivot point, Pattern/Pola Candlestick, dan analisis matematis lainnya) untuk mempelajari peluang pasar.

\subsubsection{Analisis Teknikal}

Analisis fundamental adalah analisis yang menggunakan berbagai informasi keadaan ekonomi suatu Negara, termasuk berita, laporan dan kebijakan yang dikeluarkan pemerintah, dan juga rumor untuk memprediksi harga yang akan datang pada pasar foreign exchange.

\subsubsection{Analisis Teknikal}

Setiap trader mempunyai pikiran dan pendapat yang dinyatakan melalui posisi yang mereka ambil, membantu membentuk keseluruhan sentimen pasar.Masalahnya adalah bahwa sebagai trader, tidak peduli seberapa kuat perasaan Anda. Anda tidak dapat menggerakkan pasar ke arah yang diinginkan

\subsection{Trend pada Foreign Exchange}

Secara garis besar tren dibagi menjadi 3 (tiga) yaitu Uptrend (Bullish) berarti pasar sedang dalam keadaan harga naik, Downtrend (Bearish)berarti memperlihatkan pasar sedang dalam penurunan harga, Sideways (Range Bound) atau Konsolidasi, datar dan statis itulah ciri - ciri dari pergerakan sideways, sederhananya harga tidak sedang dalam uptrend atau downtrend.

\subsection{Jenis Indikator Foreign Exchange}

Pada dasarnya ada 4 jenis indikator teknikal yang diandalkan dan sering digunakan para trader, yaitu indikator yang menunjukkan arah trend (trend following), indikator yang meng-konfirmasi arah trend (trend confirmation), 
indikator yang menunjukkan overbought dan oversold dan indikator yang membantu menentukan level exit (profit taking).

\subsection{Manajemen Risiko (Risk Management)}

Manajemen resiko adalah mengenai meminimalkan resiko dengan tujuanmemaksimalkan peluang keuntungan.Ada tiga metode risk management tools, yaitu: cut loss, switching, dan averaging.

\section{Cutloss}

Teknik ini dilakukan dengan cara menutup transaksi yang merugi sesegera mungkin dengan tujuan untuk menghindari resiko kerugian yang lebih besar.

\section{Switching}

Teknik dilakukan dengan cara menutup posisi yang rugi dan segera mengambil posisi baru yang searah dengan pergerakan harga selanjutnya. Idenya adalah untuk me-recovery kerugian yang diakibatkan oleh posisi transaksi sebelumnya.

\section{Averaging}

Averaging (atau disebut juga sebagai 'cost-averaging') merupakan teknik manajemen resiko yang cukup ekstrim karena pada dasarnya teknik ini mencoba untuk "melawan" pasar.Ide dasarnya adalah pasar tidak mungkin bergerak ke satu arah saja untuk selamanya.

\subsection{Manajemen Modal (Money Management)}

Money management ini sebenarnya merupakan bagian dari trading plan. Mengingat tingginya resiko yang akan Anda hadapi di pasar, maka Anda harus memiliki strategi pengelolaan dana yang tepat.

\subsection{Expert Advisor Foreign Exchange (Robot Foreign Exchange)}

Expert Advisor adalah suatu perangkat lunak yang diprogram khusus untuk membantu manusia dalam mengambil alih transaksi di perdagangan berjangka.

\subsection{Rencana Perdagangan (Trading Plan)}

Ungkapan bijak dalam bisnis mengatakan "jika Anda gagal membuat rencana berarti Anda merencanakan untuk gagal" (fail to plan and you plan to fail).Secara sederhana sebuah rencana trading harus memiliki 5 unsur utama, yaitu Cara pikir dalam trading (trading mindset), Tujuan, bisa jangka panjang, jangka pendek atau keduanya, Money management (termasuk manajemen resiko), Strategi trading, Rutinitas trading

\subsection{Konsep Dasar Data, Informasi, dan Pengetahuan}

\subsubsection{Data}

Data adalah deskripsi tentang benda, kejadian, aktivitas, dan transaksi, yang tidak mempunyai makna atau tidak berpengaruh secara langsung kepada pemakai.Misalnya, Anda menjumpai deretan angka seperti 6.30276 .32286 .34 
27. Anda mungkin merasakan bahwa deretan bilangan tersebut tidak memberikan makna apa pun, itulah contoh data.

\subsubsection{Informasi}

Beberapa definisi informasi yang dikemukakan oleh para ahli :

1. Jogiyanto (2008), informasi adalah data yang diolah menjadi bentuk yang berguna bagi para pemakainya.

2. Sutarman (2009), informasi adalah sekumpulan fakta (data) yang diorganisasikan dengan cara tertentu, sehingga mereka mempunyai arti bagi si penerima.

\subsubsection{Pengetahuan}

Pengetahuan (Knowledge) adalah kombinasi dari naluri, gagasan, aturan, dan prosedur yang mengarahkan tindakan atau keputusan (Alter, 1992).

\subsection{Konsep Dasar Sistem dan Subsistem \\ 2.18.1 Pengertian Sistem}

Sistem dapat didefinisikan sebagai kumpulan dari elemen - elemen berupa data, jaringan kerja dari prosedur - prosedur yang saling berhubungan, sumber daya manusia, teknologi baik hardware maupun software yang saling berinter aksi sebagai satu kesatuan untuk mencapai tujuan / sasaran tertentu yang sama.

\subsubsection{Elemen Sistem}

Ada beberapa elemen yang membentuk sebuah sistem, yaitu Tujuan, Masukan, Proses, Keluaran, Mekanisme Pengendalian, danUmpan Balik, Batas, serta Lingkungan.

\subsubsection{Subsistem dan Supersistem}

Sistem merupakan komponen dari sistem yang lebih besar, subsistem adalah sistem yang lebih kecil yang terdapat di dalam sistem tersebut.Dan supersistem adalah sistem yang lebih besar dan sangat komplek.Supersistem mengacu kepada sistem apapun yang memiliki sistem - sistem yang lebih kecil.

\subsubsection{Antarmuka Subsistem}

Antarmuka subsistem merupakan hal yang penting, sebab tanpa antarmuka ini sistem hanya berisi sekumpulan subsistem yang berdiri sendiri dan tidak saling berkaitan. Bayangkan jika dalam sebuah perusahaan, antara bagian produksi dan bagian teknologi informasi akan membangun sistem yang tidak diperuntukkan untuk menangani masalah sekarang pada bagian produksi, tetapi menangani masalah yang telah berlalu.Secara prinsip, antarmuka subsistem berupa masukan dan keluaran.Dalam prakteknya, sebuah subsistem bisa saja hanya memberikan keluaran atau hanya menerima masukan.

\subsection{Konsep Pemodelan Sistem}

UML (Unified Modelling Language) adalah 'bahasa' pemodelan untuk sistem atau perangkat lunak yang berparadigma 'berorientasi objek'. Pemodelan (modeling) ini sesungguhnya digunakan untuk penyederhanaan permasalahan - 
permasalahan yang kompleks sedemikian rupa sehingga lebih mudah dipelajari dan mudah dipahami.

\subsubsection{Use Case Diagram}

Use case adalah deskripsi fungsi dari sebuah sistem dari perspektif pengguna. Use case bekerja dengan cara mendeskripsikan tipikal interaksi antara user (pengguna) sebuah sistem dengan sistemnya sendiri melalui sebuah cerita bagaimana sebuah sistem dipakai.

\subsubsection{Activity Diagram}

Activity Diagram adalah teknik untuk mendeskripsikan logika prosedural, proses bisnis dan aliran kerja dalam banyak kasus.Activity diagram mempunyai peran seperti halnya flowchart, akan tetapi perbedaannya dengan flowchart adalah activity diagram bisa mendukung perilaku paralel sedangkan flowchart tidak bisa.

\subsubsection{Sequence Diagram}

Sequence diagramdigunakan untuk menggambarkan perilaku pada sebuah scenario. Diagram ini menunjukkan sejumlah contoh obyek dan message (pesan) yang diletakkan diantara obyek - obyek ini di dalam use case.

\subsubsection{Collaboration Diagram}

Diagram Kolaborasi atau collaboration diagram menunjukkan informasi yang sama persis dengan diagram sekuensial, tetapi dalam bentuk dan tujuan yang berbeda. Pada diagram sekuensial, keseluruhan interaksi berdasarkan urutan waktu, tetapi pada diagram kolaborasi, interaksi antar obyek atau actor ditunjukkan dengan arah panah tanpa keterangan waktu.

\subsubsection{Class Diagram}

Class diagram adalah diagram yang digunakan untuk merepresentasikan kelas, komponen - komponen kelas dan hubungan antara masing - masing kelas. Selain itu class diagram mendeskripsikan jenis - jenis objek dalam sistem dan berbagai macam hubungan statis yang terdapat diantara mereka

\subsection{Perangkat Lunak yang Digunakan}

\subsubsection{MetaQuotes Language Editor (MetaEditor)}

MQL (MetaQuotes Language) adalah bahasa pemrograman untuk memprogram Expert Advisor, Indicator ataupun script yang terdapat pada MetaEditor yang nanti digunakan pada platform MetaTrader.

\subsubsection{MetaTrader 4 (MT4)}

Aplikasi Metatrader bukan buatan brokertertentu, melainkan oleh perusahaan pengembang perangkat khusus untuk perdagangan foreign exchange, Metaquotes.Metaquotes telah membuat dua jenis Metatrader, yaitu Metatrader4 (MT4) dan Metatrader5.PlatformMetatrader 4 sudah sangat populer dan menjadi standar dari industri perbrokeran. Sejauh ini sebagian broker cenderung lebih menawarkan Metatrader 4 sebagai platform trading. 


\section{ANALISA DAN PERANCANGAN}

\subsection{Analisa Masalah}

Pada awalnya setiap trader foreign exchange melakukan trading secara manual yang mengharuskan setiap trader melakukan berbagai macam analisa, seperti menganalisa berita - berita ekonomi yang berhubungan dengan pair mata uang foreign exchange itu sendiri, analisa teknikal yang mengharuskan trader memantau pergerakan harga pada chart dengan menggunakan berbagai indikator untuk menemukan waktu yang tepat untuk melakukan order sampai dengan melakukan analisa sentimen atau analisa minat trader - trader pada pasar foreign exchange. Tapi seiring perkembangan zaman dan teknologi, bertrading dapat dilakukan secara otomatis dengan menggunakan fitur yang terdapat pada platformtrading itu sendiri.Dengan menggunakan trading otomatis, traderbisa melakukan trading dengan bantuan robot atauexpert advisor bahkan saat trader tersebut sedang sibuk dan tidak ada waktu dalam mengamati grafik.

\subsection{Analisa Sistem Trading Foreign Exchange (Forex) Secara Manual}

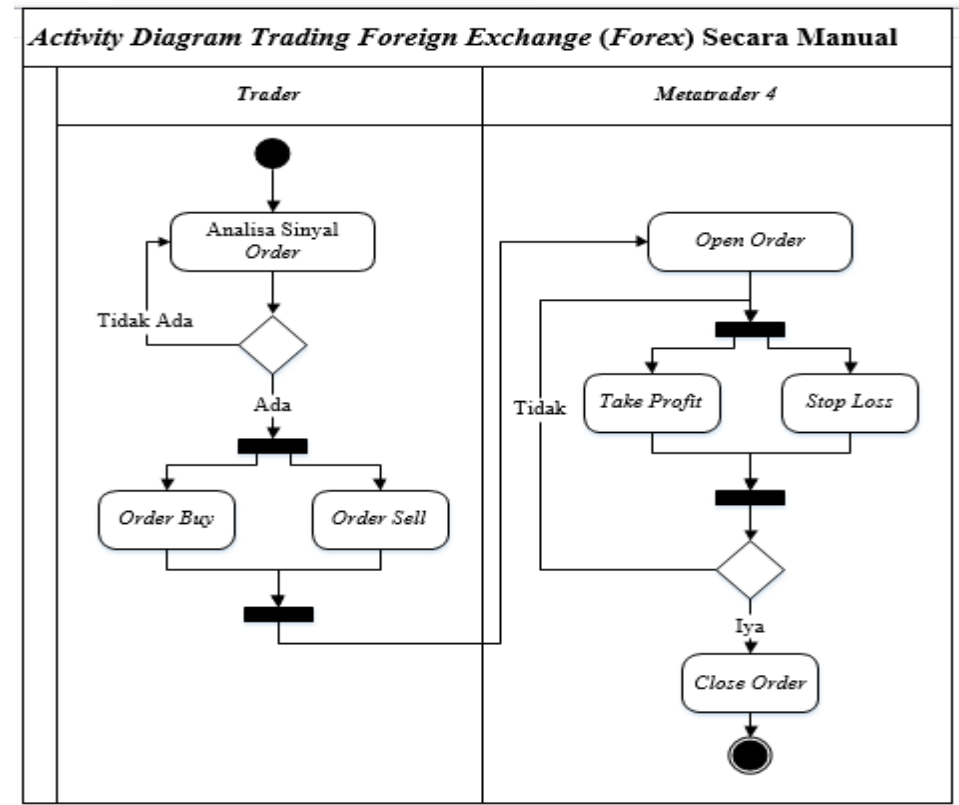

Gambar 3.1 Activity Diagram Trading Foreign Exchange (Forex) Secara Manual

\subsection{Analisa Kebutuhan Sistem}

\subsubsection{Analisa Kebutuhan Perangkat Lunak}

Perangkat lunak yang dibutuhkan untuk trading foreign exchange (forex) secara otomatis menggunakan expert advisor adalah dengan menggunakan bahasa MQL (Meta Quotes Language) untuk pembuatan expert advisor nya dan Metatrader 4 sebagai platform dalam melakukan transaksi foreign exchange (forex).

\subsubsection{Analisa Kebutuhan Perangkat Keras}

Untuk kelancaran dalam bertradingforeign exchange, maka spesifikasi minimal perangkat keras yang direkomendasikan adalah sebagai berikut :

\section{Processor : Intel Pentium 4}


2. Memori : Double Data Rate Random Access Memory (DDR RAM) 256 MegaBytes (MB)

3. Hardisk :8 GigaBytes

4. Monitor : Support $1024 \times 768$ dengan resolusi 32 bits

5. Modem : Digital Subscriber Line (DSL) atau saluran kabel.

6. Sistem operasi : Windows XP

7. Mouse dan keyboard

\subsubsection{Analisa Kebutuhan Pengguna}

Sebuah sistem yang baik adalah sistem yang mudah digunakan dan mudah dimengerti oleh pengguna (User Friendly). Sistem expert advisor foreign exchange (forex) ini akan digunakan oleh trader dalam bertransaksi foreign exchange (forex), untuk pengaturan expert advisor ini tidak banyak sehingga tidak membuat para trader bingung.

\subsubsection{Analisa Kebutuhan Expert Advisor}

Expert advisor yang akan dibangun diharapkan akan mampu memenuhi kebutuhan transaksi yang dibutuhkan para trader dalam trading foreign exchange.

1. Expert advisor dapat diinputkan nilai magic number, lots, stop loss, take profit, trailing stop, dan slippage oleh trader.

2. Expert advisor dapat melakukan order buy / order sell secara cepat, tepat dan otomatis.

3. Expert advisor dapat melakukan close order pada saat harga menyentuh harga pada stop loss atau take profit.

4. Expert advisor dapat memberikan profit pada keseluruhan transaksi.

\subsection{Analisis Penggunaan Indikator Simple Moving Average}

Moving average (MA) adalah indikator berjenis trend, yang digunakan untuk menentukan trend yang sedang berlangsung pada perdagangan foreign exchange, penggunaan moving average tidak hanya ada dalam dunia tradingforeign exchange namun juga luas pada berbagai macam teknik analisa teknikal untuk perdagangan lain, seperti saham dan lain sebagainya.Moving average mempunyai tiga varian yang berbeda dalam tingkatannya, yaituSimple Moving Average, Weighted Moving Average dan yang terakhir adalah Exponential Moving Average.

Dibawah ini pertama akan di bahas tentang simple moving average. Contoh perhitungan data menggunakan simplemoving average : Jika si A mempunyai data 21, 22, 23, 24, 25, 26, 27, 28, 29, 30, 31, 32, 33, 34, dan 35. Kemudian si A akan menerapkan metode perhitungan indikator simple moving average pada period 8 dan period 12 , maka hasilnya akan seperti ini :

Tabel 3.1 Perhitungan data menggunakan simple moving average

\begin{tabular}{|l|l|l|l|}
\hline Sampel & SMA period 8 & \multicolumn{1}{c|}{ SMA period 12 } \\
\hline 21 & - & & - \\
\hline 22 & - & & - \\
\hline 23 & - & & - \\
\hline
\end{tabular}




\begin{tabular}{|c|c|c|}
\hline 24 & - & - \\
\hline 25 & - & - \\
\hline 26 & - & - \\
\hline 27 & - & - \\
\hline 28 & $\begin{array}{l}=(21+22+23+24+25+26+2 \\
7+28) / 8=24.5\end{array}$ & - \\
\hline 29 & $\begin{array}{l}=(22+23+24+25+26+27+2 \\
8+29) / 8=25.5\end{array}$ & - \\
\hline 30 & $\begin{array}{l}=(23+24+25+26+27+28+2 \\
9+30) / 8=26.5\end{array}$ & - \\
\hline 31 & $\begin{array}{l}=(24+25+26+27+28+29+3 \\
0+31) / 8=27.5\end{array}$ & - \\
\hline 32 & $\begin{array}{l}=(25+26+27+28+29+30+3 \\
1+32) / 8=28.5\end{array}$ & $\begin{array}{l}=(21+22+23+24+25+26+27+28+ \\
29+30+31+32) / 12=26.5\end{array}$ \\
\hline 33 & $\begin{array}{l}=(26+27+28+29+30+31+3 \\
2+33) / 8=29.5\end{array}$ & $\begin{array}{l}=(22+23+24+25+26+27+28+29+ \\
30+31+32+33) / 12=27.5\end{array}$ \\
\hline 34 & $\begin{array}{l}=(27+28+29+30+31+32+3 \\
3+34) / 8=30.5\end{array}$ & $\begin{array}{l}=(23+24+25+26+27+28+29+30+ \\
31+32+33+34) / 12=28.5\end{array}$ \\
\hline 35 & $\begin{array}{l}=(28+29+30+31+32+33+3 \\
4+35) / 8=31.5\end{array}$ & $\begin{array}{l}=(24+25+26+27+28+29+30+31+ \\
32+33+34+35) / 12=29.5\end{array}$ \\
\hline
\end{tabular}

Dibawah ini penerapan 2 buah indikator simple moving average

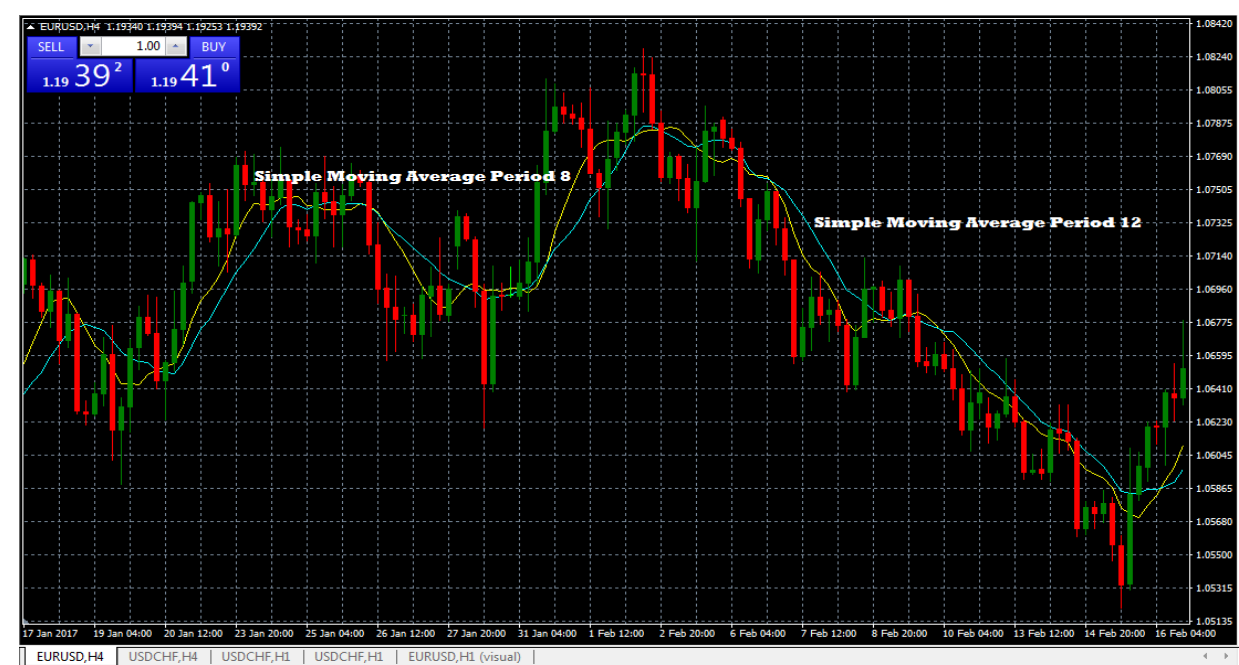

Gambar 3.2Simple moving average period 8 dan 12 pada pair EUR/USD

Dengan penggunaan dua Simple Moving Average dengan dua atau tiga periode yang berbeda, dapat lebih akurat lagi memprediksikan kemana harga akan bergerak.Pada gambar 3.2 diatas, apabila simple moving average dengan periode yang lebih kecil yaitu periode 8 ( ditunjukkan dengan garis grafik berwarna kuning ), jika berada dibawah dari garis grafik simple moving average yang periodenya lebih besar, pada gambar diwakili dengan periode 12 dengan garis berwarna biru, maka itu merupakan indikasi harga sedang dalam trend turun. 
Dan demikian pun sebaliknya, apabila periode lebih kecil berada di atasdari simple moving average periode yang lebih besar, maka trend mata uang sedang dalam trend naik atau uptrend.Apabila rentang antara kedua simple moving average semakin besar dan lebar, maka kemungkinan besar trend akan terus berlangsung, namun apabila mulai terjadi penyempitan jarak diantara kedua priode simple moving average tersebut, dan sampai hingga terjadi perpotongan kembali, dapat disimpulkan bahwa trend harga yang berlangsung sudah berakhir.Mengenai rentang waktu periode moving average yang dipakai, tidak ada aturan khusus yang menentukan berapa lama sebaiknya periode simple moving average terbaik dalam usaha menentukan trend dan memprediksi harga. Memang dibutuhkan banyak pengalaman untuk menemukan berapa periode terbaik yang dapat digunakan, karena pergerakan nilai mata yang terus bergerak dimanis, maka proses mencoba, dan mencoba lagi adalah hal yang sangat dianjurkan.Namun memang dianjurkan, bahwa tidak menggunakan periode yang lebih besar diatas 40, karena hal tersebut akan mengurangi sensitivitas simple moving average dalam menentukan trend harga yang akan berlangsung.Dibawah ini dibuatkan tabel untuk membaca indikator simple moving average ini.

Tabel 3.2 Posisi simple moving average dan artinya

\begin{tabular}{|c|l|l|}
\hline No & \multicolumn{1}{|c|}{ Posisi Simple Moving Average } & \multicolumn{1}{|c|}{ Arti } \\
\hline 1 & Simple moving average berada dibawah harga. & Kondisi bullish/ trend naik. \\
\hline 2 & Simple moving average berada diatas harga. & $\begin{array}{l}\text { Kondisi bearish / trend } \\
\text { menurun. }\end{array}$ \\
\hline 3 & $\begin{array}{l}\text { Simple moving average memotong harga dari } \\
\text { bawah. }\end{array}$ & $\begin{array}{l}\text { Perubahan trend menuju } \\
\text { bearish } .\end{array}$ \\
\hline 4 & $\begin{array}{l}\text { Simple moving average memotong harga dari } \\
\text { atas. }\end{array}$ & $\begin{array}{l}\text { Perubahan trend menuju } \\
\text { bullish } .\end{array}$ \\
\hline 5 & $\begin{array}{l}\text { Simple moving average periode lebih pendek } \\
\text { memotong simple moving average periode lebih } \\
\text { panjang dari bawah. }\end{array}$ & $\begin{array}{l}\text { Perubahan trend menuju } \\
\text { bullish } .\end{array}$ \\
\hline 6 & $\begin{array}{l}\text { Simple moving average periode lebih pendek } \\
\text { memotong simple moving average periode lebih } \\
\text { panjang dari atas. }\end{array}$ & $\begin{array}{l}\text { Perubahan trend menuju } \\
\text { bearish } .\end{array}$ \\
\hline 7 & $\begin{array}{l}\text { Simple movingaverage dengan periode lebih } \\
\text { panjang berada diatassimple moving average } \\
\text { berperiode lebih pendek. }\end{array}$ & $\begin{array}{l}\text { Kondisi bearish / trend } \\
\text { menurun. }\end{array}$ \\
\hline 8 & $\begin{array}{l}\text { Simple moving average dengan periode lebih } \\
\text { panjang berada dibawahsimple moving average } \\
\text { berperiode lebih pendek. }\end{array}$ & Kondisi bullish / trend naik \\
\hline
\end{tabular}

\subsection{Analisa Manajemen Risiko (Risk Management)}

Dalam trading foreign exchange, risiko itu bisa berupa kehilangan sebagian atau seluruh dana yang diinvestasikan. Untuk meminimalisir risiko itu, diperlukan manajemen risiko yang baik. Dalam pembangunan expert advisor menggunakan simple moving average ini akan menggunakan manajemen risiko seperti stop loss, take profit dan juga trailing stop

\subsection{Analisa Manajemen Modal}


Contoh seorang trader memiliki dana sebesar \$100 di akunnya, lalu ia tetapkan risiko maksimal untuk setiap transaksi, katakanlah $5 \%$ per trade. Ini artinya adalah kerugian maksimal yang mungkin akandidapat oleh trader tersebut pada setiap transaksi adalah sebesar 5\% x $\$ 100=\$ 5$ jadi, resiko untuk setiap transaksi yang dlakukan tidak boleh lebih dari \$5.Seandainya transaksi pertama si trader mengalami kerugian, maka dananya masih tersisa sebesar $\$ 95$ yang masih bisa melakukan transaksi trading sekitar 19 kali lagi dan jika nilai kontrak \$0.01 pada setiap pips / points maka untuk setiap \$1 dapat menahan 100 pips pergerakan harga kalau $\$ 95$ maka, $\$ 95 \times 100=9500$ pips, 9500 pips ini sudah dapat menahan pergerakan rata - rata pergerakan pips harian dari suatu pips foreign exchange.

\subsection{Perancangan UML (Unified Modelling Language)}

Setelah dilakukan analisa, maka dilakukan perancangan sistem, berikut perancangan UML (Unified Modelling Language) Expert Advisor Foreign Exchange menggunakan Simple Moving Average

\subsubsection{Use Case Diagram}

Diagram use case ini menunjukkan interaksi antara use case dan actor untuk sistem expert advisor dalam trading foreign exchange (forex).

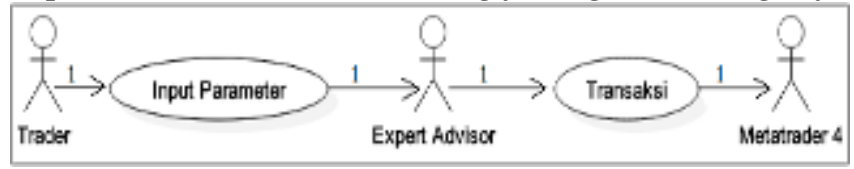

Gambar 3.3Use case expert advisor foreign exchange (forex)

\subsubsection{Use Case Diagram Input Parameter}

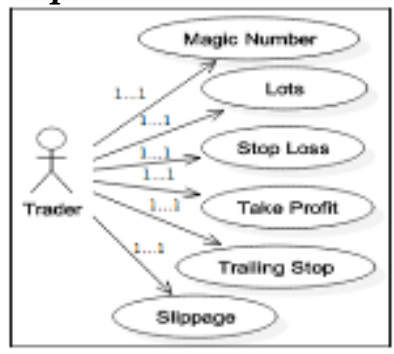

Gambar 3.4Use case diagram input parameter

\subsubsection{Use Case Diagram Transaksi}




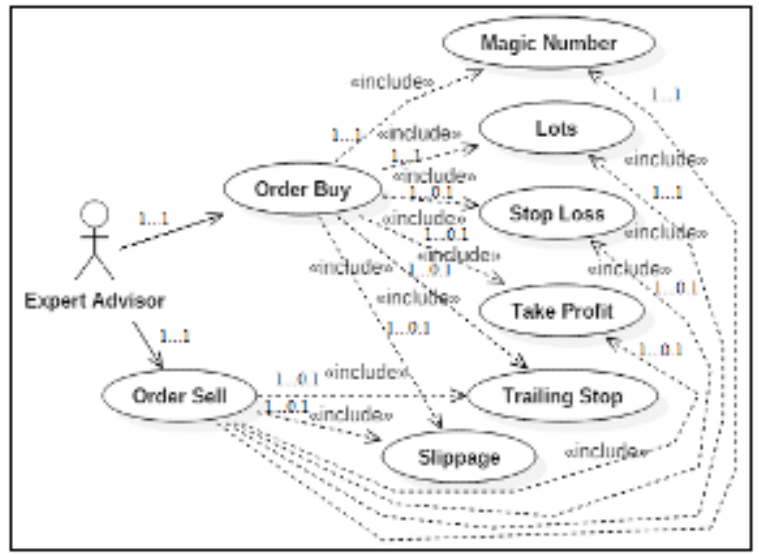

Gambar 3.5Use case transaksi

\subsubsection{Activity Diagram}

\subsubsection{Activity Diagram Input Parameter}

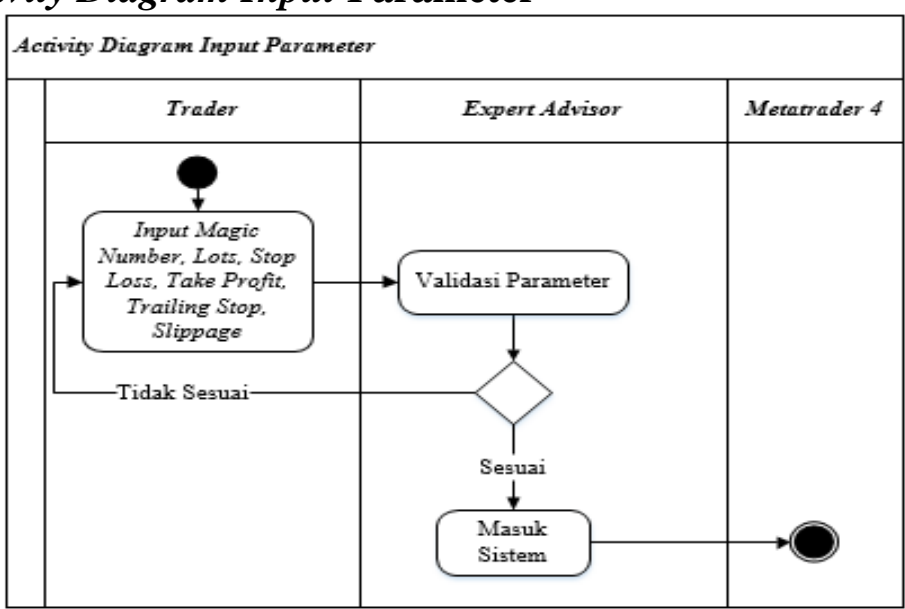

Gambar 3.6Activity diagram input parameter

\subsubsection{Activity Diagram Transaksi}




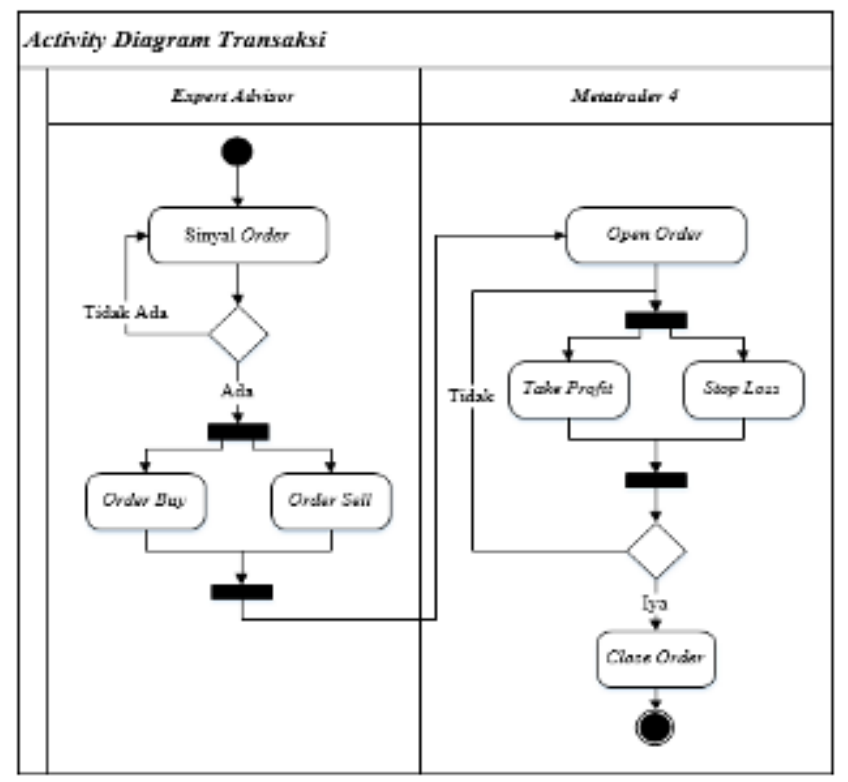

Gambar 3.7Activity diagram transaksi

\subsubsection{Sequence Diagram}

Sequence diagram digunakan untuk menggambarkan perilaku pada sebuah scenario atau menunjukkan aliran fungsionalitas dalam use case, sequence diagram ini menunjukkan serangkaian pesan yang dipertukarkan oleh obyek - obyek yang melakukan suatu tugas atau aksi tertentu.

\subsubsection{Sequence Diagram Input Parameter}

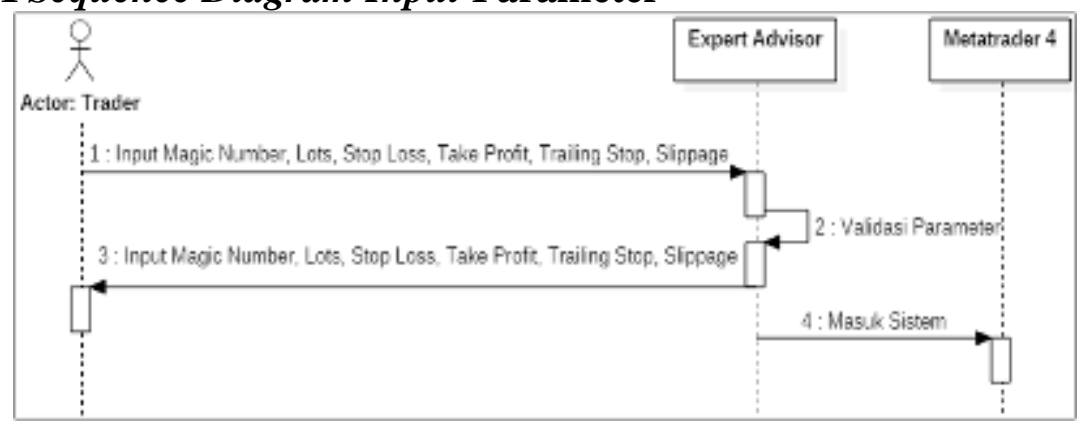

Gambar 3.8Sequence diagram input parameter

\subsubsection{Sequence Diagram Transaksi}

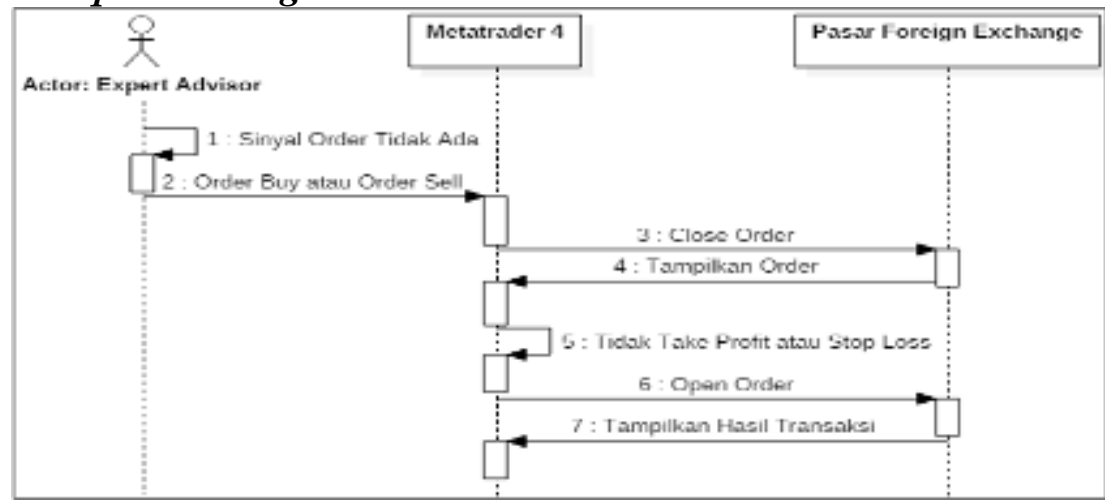

Gambar 3.9Sequence diagram transaksi 


\subsubsection{Collaboration Diagram}

Pada dasarnya diagram ini sama dengan diagram sekuensial (sequence diagram), diagram ini berbentuk seperti bintang, dengan beberapa obyek yang berkomunikasi dengan sebuah obyek pusat, arstiek sistem menggunakan diagram ini untuk menyimpulkan bahwa sistem yang dibangun terlalu tergantung pada obyek pusat, dan merancang ulang obyek - obyek untuk mendistribusikan proses secara merata. Interaksi demikian akan sulit dilihat jika menggunakan diagram sekuensial saja.

\subsubsection{Collaboration Diagram Input Parameter}

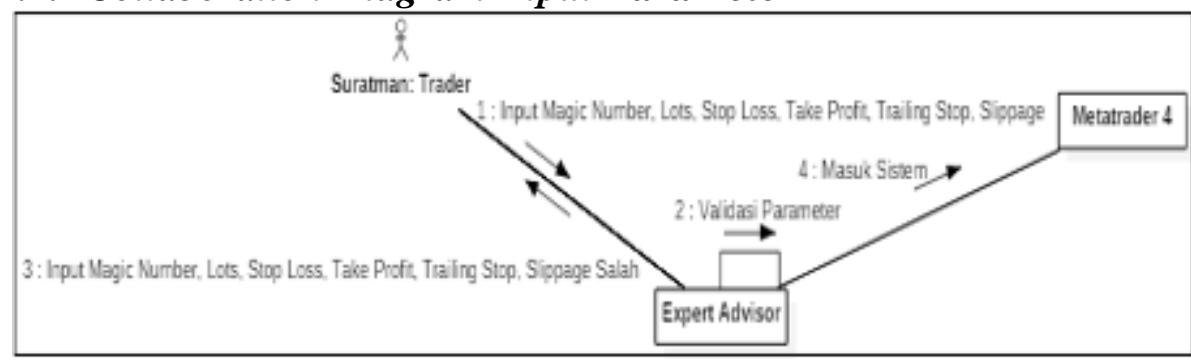

Gambar 3.10Collaboration diagram input parameter

\subsubsection{Collaboration diagram transaksi}

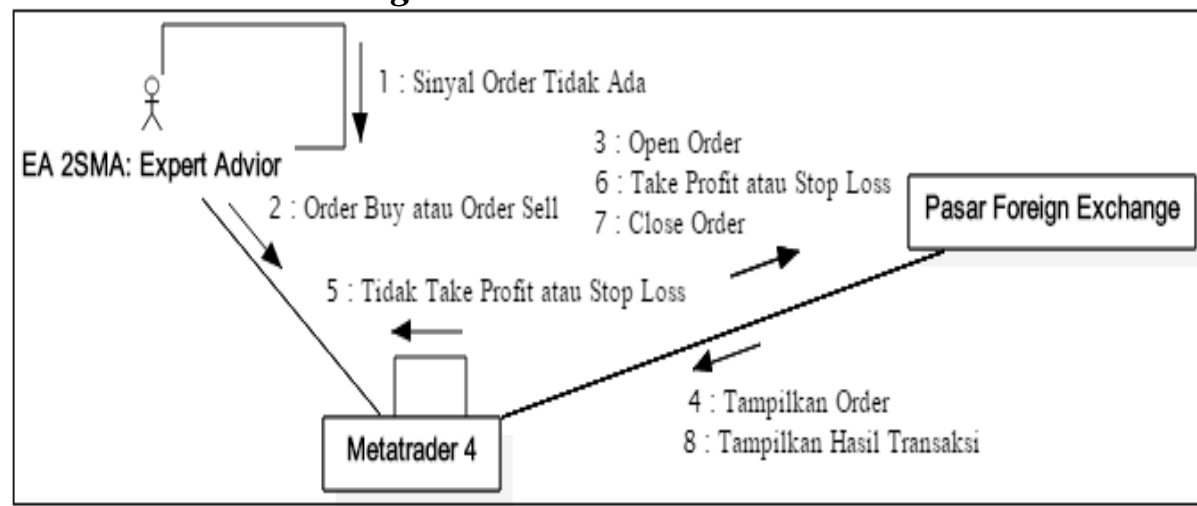

Gambar 3.11Collaboration diagram transaksi

\subsubsection{Class Diagram}

Diagram kelas atau class diagram menunjukkan interaksi antar kelas ke dalam sistem, kelas mengandung informasi dan tingkah laku yang berkaitan dengan sistem tersebut.

\begin{tabular}{|c|c|c|c|c|}
\hline Expert Advisor & \multirow[b]{4}{*}{$1 \ldots 1$} & & \multirow[b]{4}{*}{$1 \ldots n$} & \multirow[b]{3}{*}{ Pasar Foreign Exchange } \\
\hline \multirow{5}{*}{$\begin{array}{l}\text {-Magic Number } \\
\text {-Lots } \\
\text {-Stop Loss } \\
\text {-Take Profit } \\
\text {-Trailing Stop } \\
\text {-Slippage } \\
\text { +Terima Input Parameter } \\
\text { +Validasi Parameter } \\
\text { +Sinyal Order } \\
\text { +Order Buy } \\
\text { +Order Sell }\end{array}$} & & \multirow{4}{*}{$\begin{array}{l}\text { Metatrader } 4 \\
\text { +Implementasikan Expert Advisor } \\
\text { +Open Order } \\
\text { +Tampilkan Order } \\
\text { +Tampilkan Hasil Transaksi }\end{array}$} & & \\
\hline & & & & \\
\hline & & & & \multirow{2}{*}{$\begin{array}{l}\text { +Terima Open Order } \\
\text { +Take Profit } \\
\text { +Stop Loss } \\
\text { +Close Order }\end{array}$} \\
\hline & & & & \\
\hline & & & & \\
\hline
\end{tabular}

Gambar 3.12 Class diagram expert advisor 


\subsection{Strategi Expert Advisor}

1. Pada dasarnya expert advisor ini bekerja dengan memantau pergerakan harga pasar pada chart, dengan tetap mengacu pada trend harga pasar yang dihasilkan oleh 2 indikator simple moving average, yaitu simple moving average period 8 dan simple moving average period 12 .

2. Simple moving average ini akan diimplementasikan pada harga rata - rata penutupan harga pada 8 dan 12 candlestick (grafik lilin) terakhir.

3. Jika simple moving averageperiod $8>$ simple moving averageperiod 12 atau simple moving averageperiod 8 berada di atas simple moving averageperiod 12 maka expert advisor akan melakukan order buy, jika simple moving average 8 <simple moving average 12 atau simple moving averageperiod 8 berada di bawah simple moving averageperiod 12 maka expert advisor akan melakukan order sell.

4. Expert advisor ini menggunakan stop loss untuk membatasi kerugian pada saat melakukan order, take profit untuk mengambil keuntungan pada setiap transaksi yang dilakukan, dan trailing stop yang berfungsi sama seperti stop loss namun trailing stop ini digunakan untuk mengubah nilai stop loss untuk mengunci profit secara otomatis dalam kelipatan nilai tertentu serta slippage yang digunakan sebagai toleransi harga ketika akan melakukan order.

\section{HASIL DAN PEMBAHASAN}

\subsection{Implementasi Sistem}

Dalam implementasi expert advisor ini, spesifikasi minimal yang digunakan sebagai berikut :

1. Processor : Intel Pentium 4

2. Memori : Double Data Rate Random Access Memory (DDR RAM) 256 MegaBytes (MB)

3. Hardisk :8 GigaBytes

4. Monitor : Support $1024 \times 768$ dengan resolusi 32 bits

5. Modem : Digital Subscriber Line (DSL) atau saluran kabel.

6. Sistem operasi : Windows XP

7. Mouse dan keyboard

Dalam impementasi expert advisor ini broker yang digunakan adalah broker XM dengan menggunakan platform metatrader 4 yang akan digunakan sebagai aplikasi transaksi trading dan pengimplementasian serta pengujian expert advisor yang telah dibuat.

\subsection{Implementasi Pengujian Expert Advisor}

Pengujian bertujuan untuk memastikan semua fungsi sistem yang dibangun bekerja dengan baik.Tahap pengujian ini dilakukan menggunakan metode black box. Pengujian black box adalah pengujian yang berdasarkan fungsi dasar dari masing-masing proses pada program. 
Tabel 4.1 Pengujian validasi expert advisor

\begin{tabular}{|c|l|l|l|l|l|}
\hline No & $\begin{array}{c}\text { Data } \\
\text { Pengujian }\end{array}$ & Cara Pengujian & $\begin{array}{l}\text { Hasil Yang } \\
\text { Diharapkan }\end{array}$ & Pengamatan & Ket \\
\hline 1. & $\begin{array}{l}\text { Menguji } \\
\text { validasi } \\
\text { expert } \\
\text { advisor }\end{array}$ & $\begin{array}{l}\text { Klik enable } \\
\text { automated } \\
\text { trading (CTRL } \\
\text { +E) lalu klik } \\
\text { expert advisor } \\
\text { "EA 2SMA } \\
\text { SURATMAN" }\end{array}$ & $\begin{array}{l}\text { Muncul simbol } \\
\text { senyum pada } \\
\text { layar kanan } \\
\text { atas } \text { chart, dan } \\
\text { juga muncul } \\
\text { form input } \\
\text { parameter pada } \\
\text { chart }\end{array}$ & $\begin{array}{l}\text { Muncul simbol } \\
\text { senyum pada } \\
\text { layar kanan } \\
\text { atas chart, dan } \\
\text { juga muncul } \\
\text { form input } \\
\text { parameter pada } \\
\text { chart }\end{array}$ & OK \\
\hline
\end{tabular}

Tabel 4.2 Pengujian validasi parameter

\begin{tabular}{|c|l|l|l|l|l|}
\hline No & $\begin{array}{c}\text { Data } \\
\text { Pengujian }\end{array}$ & \multicolumn{1}{|c|}{ Cara Pengujian } & $\begin{array}{l}\text { Hasil Yang } \\
\text { Diharapkan }\end{array}$ & Pengamatan & Ket \\
\hline 1. & $\begin{array}{l}\text { Menguji } \\
\text { validasi } \\
\text { parameter }\end{array}$ & $\begin{array}{l}\text { Klik expert advisor "EA } \\
\text { 2SMA SURATMAN" } \\
\text { pada navigator list lalu } \\
\text { isikan nilai parameter } \\
\text { MagicNumber, Lots, } \\
\text { Stoploss, Takeprofit, } \\
\text { Trailingstop, dan } \\
\text { Slippage }\end{array}$ & $\begin{array}{l}\text { Expert } \\
\text { advisor } \\
\text { melakukan } \\
\text { order }\end{array}$ & $\begin{array}{c}\text { Expert } \\
\text { advisor } \\
\text { melakukan } \\
\text { order }\end{array}$ & OK \\
& & & \\
\hline
\end{tabular}

4.3 Implementasi Antarmuka (Interface)

Berikut adalah tampilan antarmuka pada expert advisor yang telah dibangun.

\subsubsection{Tampilan Input Parameter}

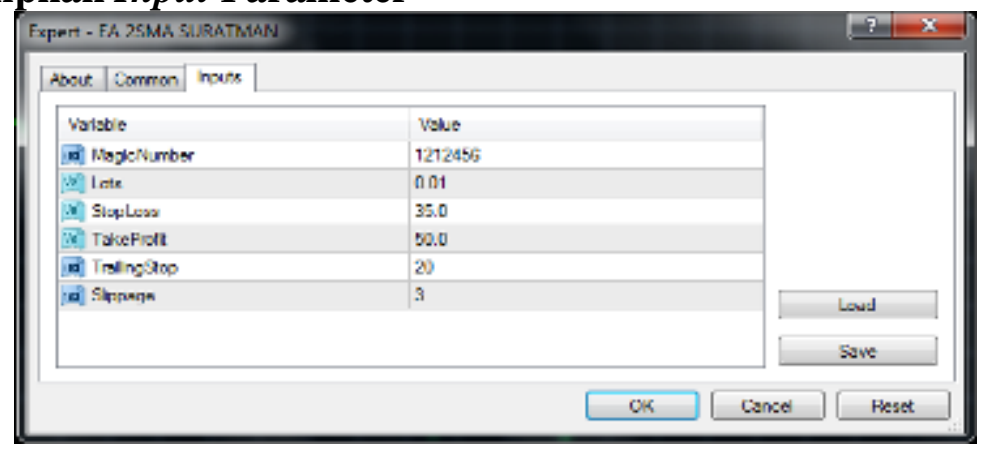

Gambar 4.1 Tampilan input parameter 


\subsubsection{Tampilan Order Pada Chart}

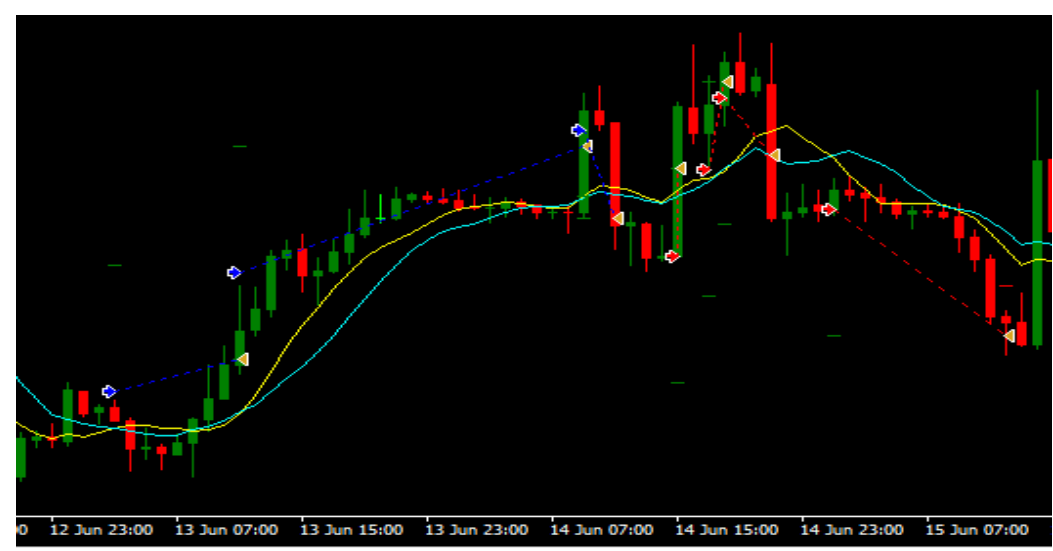

Gambar 4.2 Tampilan order pada pair EUR/USD

\subsubsection{Tampilan Order Yang Sedang Berjalan}

\begin{tabular}{|c|c|c|c|c|c|c|c|c|c|c|c|}
\hline Order & Time & Type & Size & Symbol & Price & $S / L$ & $T / P$ & Price & Commi... & Swap & Profit \\
\hline 3 4025003 & 2017.08.30 20:21:28 & sell & 0.01 & eurusd & 1.18951 & 0.00000 & 0.00000 & 1.18909 & 0.00 & 0.07 & $0.42 \times$ \\
\hline S 4112063 & $2017.08 .3117: 59: 13$ & sell & 0.01 & eurusd & 1.18921 & 1.19275 & 1.18425 & 1.18909 & 0.00 & 0.00 & $0.12 \times$ \\
\hline 马 4112079 & 2017.08.31 17:59:16 & sell & 0.01 & eurusd & 1.18926 & 1.19274 & 1.18424 & 18909 & 0.00 & 0.00 & $0.17 \times$ \\
\hline 4112103 & 2017.08 .31 17:59:19 & sell & 1 & eurusd & 1.18940 & 1.19285 & 35 & 09 & 0 & 00 & 0.31 \\
\hline
\end{tabular}

Gambar 4.3 Tampilan order yang dilakukan pada pair EUR/USD

\subsubsection{Tampilan Order Yang Ditutup}

\begin{tabular}{|l|r|r|r|r|r|r|r|r|r|r|r|}
\hline Order & Time & Type & Size & Symbol & Price & S/L & T/P & Time & Price & Swap & Profit \\
\hline \hline S 4019270 & $2017.08 .3019: 18: 06$ & sell & 0.01 & eurusd & 1.19216 & 1.19564 & 1.18714 & $2017.08 .3019: 21: 52$ & 1.19213 & 0.00 & 0.03 \\
\hline \hline 4019271 & $2017.08 .3019: 18: 07$ & sell & 0.01 & eurusd & 1.19218 & 1.19568 & 1.18718 & $2017.08 .3019: 21: 52$ & 1.19211 & 0.00 & 0.07 \\
\hline
\end{tabular}

Gambar 4.4 Tampilan order pair EUR/USD yang ditutup

\section{KESIMPULAN}

Dari hasil penelitian, implementasi serta pengujian yang telahdilakukansecaraumum, maka dapatditarikkesimpulansebagaiberikut:

1. Dengan adanya expert advisor EA 2SMA SURATMAN ini trader tidak perlu memantau layar grafik secara terus menerus untuk menemukan waktu yang tepat melakukan order karena expert advisor ini dapat melakukan order secara otomatis dengan sinyal yang diberikan 2 buah simple movingaverage dan expert advisor ini bekerja 24 jam non-stop.

1. Expert advisor EA 2SMA SURATMAN ini akan disiplin dalam mengikuti aturan yang telah diimplementasikan ke dalamnya artinya expert advisor ini tidak akan melanggar aturan yang telah diimplementasikan ke dalamnya, tidak seperti trader yang terkadang tidak disiplin dalam mengikuti aturannya.

2. Expert advisor ini menggunakan stop loss untuk meminimalisir kerugian pada saat trading, dan juga terdapat take profit dalam membatasi jumlah keuntungan serta trailing stop untuk mengunci keuntungan agar tidak menjadi kerugian, karena adanya fitur ini maka meminimalisir trader agar tidak tertekan saat mengalami kerugian. 
Berikut saran-saran dalam penggunaan expert advisor serta untuk penelitian lanjutan jika diperlukan :

1. Agar expert advisor EA 2SMA SURATMAN ini bekerja dengan baik, diharapkan menggunakan VPS Forex (Virtual Private Server Foreign Exchange) agar tidak terjadi masalah koneksi pada saat expert advisor sedang dijalankan atau melakukan transaksi.

2. Diharapkan kedepannya expert advisor EA 2SMA SURATMAN ini dapat dikembangkan lagi agar kinerjanya lebih optimal

3. Diharapkan para trader pemula harus memahami dasar - dasar dalam bertradingforeign exchange sampai dengan mekanisme kerja foreign exchangeserta cara kerja expert advisor yang digunakan agar dapat melakukan tradingdengan baik.

\section{DAFTAR PUSTAKA}

Djahir, Yulia, Dewi Pratita, Bahan Ajar Sistem Informasi Manajemen, Yogyakarta: Deepublish, 2014

Faizal, M, Elvianna, Dedy Jauhari, Ricak Agus Setiawan, Moch Rizki

Romdoni, Buku Panduan Penulisan Laporan Kerja Praktek Dan Skripsi Sekolah Tinggi Teknologi Indonesia, Tanjungpinang, 2014.

Hidayat, Taufik, Kamus Populer Istilah Investasi, Jakarta: MediaKita, 2011

Kadir Abdul, Pengenalan Sistem Informasi, Yogyakarta: Andi, 2003

Maniah, Dim Hamidin, Analisis dan Perancangan Sistem Informasi Pembahasan Secara Praktis dengan Contoh Kasus, Yogyakarta: Deepublish, 2017

Mulyani, Sri, Metode Analisis dan Perancangan Sistem, Bandung: Abdi Sistematika, 2016

Munawar, Pemodelan Visual dengan UML, Yogyakarta: Graha Ilmu, 2005, Edisi pertama

Muslihudin Muhamad, Oktafianto ,Analisis dan Perancangan Sistem Informasi Menggunakan Model Terstruktur dan UML, Yogyakarta: Andi, 2016

Nugroho Adi, Rekayasa Perangkat Lunak Berorientas Objek dengan Metode USDP, Yogyakarta: Andi, 2010

Sholiq, Pemodelan Sistem Informasi Berorientasi Obyek Dengan UML, Yogyakarta: Graha Ilmu, 2006, Edisi pertama

Suharto T, Frento, Mengungkap Rahasia Forex, Jakarta: PT Elex Media Komputindo, 2013, Edisi ke 3

VerdiYasin, rekayasa Perangkat Lunak Berorientasi Objek, 2013.

W.Ismanthono, Henricus, Kamus Istilah Ekonomi dan Bisnis, Jakarta: Kompas, 2010

Al fatta Hanif, "Analisis dan perancangan sistem informasi untuk keunggulan bersaing perusahaan dan organisasi modern", 2007, diakses dari :https://books.google.co.id/books?id=oHi8C1W4N7wC\&printsec=frontcover\& source $=$ gbs_ge_summary_r\&cad=0\#v=onepage \&q\&f=false, pada tanggal 20 juni 2017 pukul 21:34 
Denifauji, "Perangkat lunak (software)", diakses dari :https://www.scribd.com/document/49903016/PERANGKAT-LUNAK, pada tanggal 20 juni 2017 pukul 22:02

Anonim, "Apa Itu Metatrader", Seputarforex, 2017, diakses dari :http://www.seputarforex.com/belajar/metatrader/, pada tanggal 3 juni 2017 pukul 12:21

Anonim, "Belajar Mengenal Risk dan Money Management dalam Forex", Belajarforex, 2014, diakses dari :http://belajarforex.guru/belajar-mengenalrisk-dan-money-management-dalam-forex/, pada tanggal 29 mei 2017 pukul 23:13

Anonim, "Risk Management \& Money Management", Foreximf, 2014, diakses dari :http://www.foreximf.com/belajar-forex-2/mahir/riskmanagement-money-management/, pada tanggal 29 mei 2017 pukul 22:32

Martin, "4 Jenis Indikator Teknikal Yang Penting (1)", Seputarforex, 2014, diakses dari

:http://www.seputarforex.com/artikel/forex/lihat.php?id=179091\&title=4_jenis _indikator_teknikal_yang_penting_1, pada tanggal 29 mei 2017 pukul 20:18

Martin, "Membuat Sebuah Rencana Trading (1)", Seputarforex, 2014, diakses dari

:http://www.seputarforex.com/artikel/forex/lihat.php?id=162768\&title=membu at_sebuah_rencana_trading_1, pada tanggal 30 mei 2017 pukul 20:17

Parmadita, “Apa itu Robot Trading Forex (EA)?”, Seputarforex, 2012, diakses dari :

http://www.seputarforex.com/artikel/forex/lihat.php?id=85865\&title=apa_itu_e a, pada tanggal 30 mei 2017 pukul 14:10

Vendy, "Belajar Membuat EA (Bagian 1) - Pengenalan Bahasa MQL", Forextradingforliving, 2016, diakses dari :http://www.forextradingforliving.com/pemrograman-mql/belajar-membuat-eabagian-1-pengenalan-bahasa-mql/, pada tanggal 3 juni 2017 pukul 12:04 